\title{
Squamous Cell Carcinoma of the Breast: About a Case and Review of the Literature
}

\section{Serraj Andaloussi*, M Ennachit and M Elkerroumi}

Mohamed 6 Centre for the Treatment of Cancer, Ibn Rochd University Hospital Center, Casablanca, Morocco

*Corresponding Author: M Serraj Andaloussi, Mohamed 6 Centre for the Treatment of Cancer, Ibn Rochd University Hospital Center, Casablanca, Morocco.
Received: March 11, 2020

Published: May 11, 2020

(C) All rights are reserved by $\mathbf{M}$ Serraj

Andaloussi., et al.

\begin{abstract}
Squamous cell carcinoma of the breast is a rare metaplastic tumour with non-specific clinical and radiological features. Treatment is based on surgery, radiotherapy and chemotherapy. The prognosis remains pejorative.

We report a case of squamous cell carcinoma of the breast, in a patient of 39 years, having consulted at the Mohammed IV centre for the treatment of cancers at CHU Casablanca. Through this case and in the light of the literature, we specify the different characteristics of this particular form of breast cancer which remains rare.
\end{abstract}

Keywords: Squamous Cell Carcinoma; Breast; Radiotherapy; Chemotherapy

\section{Introduction}

The carcinoma squamous of the breast is very rare, it represent $0.1 \%$ to $2 \%$ of all invasive breast carcinomas. The clinic and radiology are not specifics. It is characterized by fast evolution. The treatment is similar to infiltrating ductal carcinomas and it is based on surgery, radiotherapy and chemotherapy. The prognosis seems to be comparable to that of undifferentiated carcinomas.

\section{Observation}

Madame G. CH, 42 years old, mother of 6 children, with no particular pathological history, presenting for 6 months a nodule in the left breast which increased rapidly in volume until the occupation of almost the entire breast. The initial examination objectified a mass of the external superior quadrant (QSE) of $10 \mathrm{~cm}$ irregular mobile hard, clinically classified T3N0Mx.

The echo mammography showed the presence of a large lesion process which occupies almost the entire left breast hypothome heterogeneous of irregular contours, moderately vascularized with the doppler measuring $12 \times 10 \mathrm{~cm}$, with ipsilateral axillary lymphadenopathy about $1 \mathrm{~cm}$ long axis. This echo-mammographic aspect is classified ACR5. A trucut biopsy was performed, returning in favor of a metaplastic carcinoma, of epidermoid type, of grade SBRIII. The patient benefited from a pre-chemotherapy assessment (thoraco-abdomino-pelvic CT, and bone scintigraphy) normal income, then was referred to the oncology department where she received 4 courses of anthracyclines (AC 60) then was sent to our department for surgical management. The examination found a voluminous ulcerative-budding lesion taking up almost the entire left breast with a homolateral axillary ADP of $1.5 \times 2 \mathrm{~cm}$ mobile compared to the 2 plans; the right breast, the right axillary hollow and the other devices were without particularity.
The patient therefore benefited from a total mastectomy with lymph node dissection. Histological examination revealed a cancerous proliferation infiltrating ulcerated widely in ischemic necrosis and including vascular emboli. The cells are preserved type squamous with significant atypia cytonuclear, some are giant and multinucleated, others are large nuclei budding or eosinophilic or with hyperchromatic nucleus or with mottled chromatin. Mitosis is abnormally frequent. The stroma is fibrous or inflammatory and seat of mineralization. The tumour measured $11 \mathrm{~cm}$ long axis, with peritumoral vascular emboli of grade III SBR, with massive lymph node metastases and capsular intrusion in the form of a lymph node measuring $4 \mathrm{~cm}$ along the long axis. In the immunohistochemical study, the proliferative index was estimated at $35 \%$. The hormone receptors and the percept test were negative. There is no other component seen. The diagnosis retained was that of a metaplastic carcinoma of the epidermal carcinoma type. The patient was re- referred to the oncology department for adjuvant treatment.

\section{Discussion}

Primary squamous cell carcinomas of the breast are rare with a frequency of 0.1 to $2 \%$ of all breast carcinomas; they belong to the heterogeneous group of mammary metaplastic carcinomas [1,2]. The etiopatogenesis remains controversial [3].

Age occurred is like other breast carcinomas; it affects women between 31 and 83 years with a peak of 55 years [3].

Its diagnosis is often made at the palpable bulky mass stage, escaping screening campaigns [4].

Clinically, it is in the form of a breast mass with an average size of $5 \mathrm{~cm}$ with extremes of 2 to $16 \mathrm{~cm}$. In addition, large tumours tend to undergo central cystic degeneration with invasion and ul- 

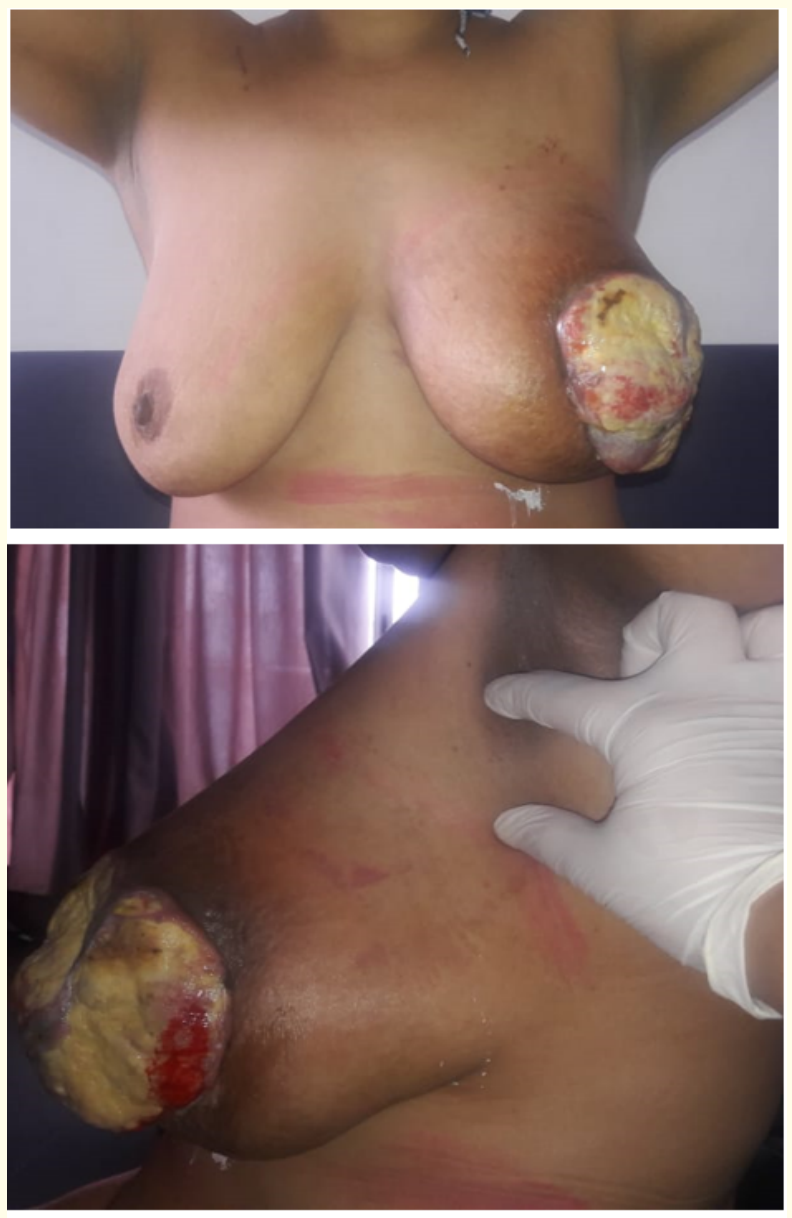

Figure 1: Macroscopic appearance of the tumor: a large ulcer- budding lesion with superinfection taking almost the entire left breast with a homolateral axillary ADP of $1.5 \times 2 \mathrm{~cm}$ mobile compared to the 2 plans.

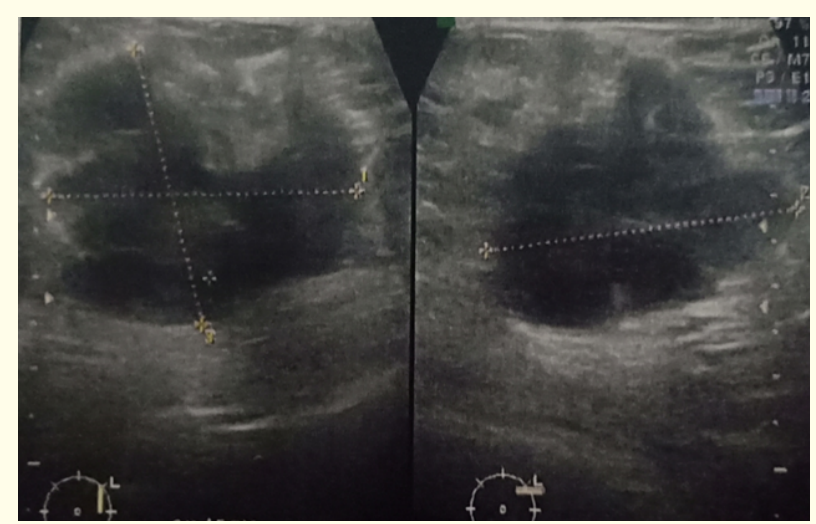

Figure 2: Ultrasound appearance showing a heterogeneous hypoechoic formation of irregular contours. BIRADS V class examination of the ACR.

ceration of the surrounding skin [5], which poses a problem of its primary or secondary origin [3].

Radiologically, the appearance is not specific. This is usually a rounded mass without spikes, partially irregular necrotic or cystic centre which explains the appearance nickname mystique or abscessed which is found [6].
In the case of pure epidermoid metaplasia, the possibility of skin carcinoma or metastasis must be eliminated [7].

The immunohistochemistry shows an expression of the epithelial tumour cell cytokeratin's high molecular weight noted moment the CK14, CK5/6 and CK17 [8]. However, most of these tumours do not express hormone receptors, as does the amplification of Her 2, which agrees with our observation. On the other hand, the proliferative nature (Ki 67) has been strongly demonstrated by the study carried out by Grenier., et al [5].

The treatment of squamous cell carcinoma of the breast is similar to infiltrative ductal carcinoma. Conservative surgery is possible; For larger tumours, mastectomy with lymph node dissection is indicated followed by radiotherapy and chemotherapy. The use of hormone therapy is limited by the absence of the hormone dependence of this cancer [9]. From the same as for the Herceptin usual negativity to the percept test [10].

\section{Conclusion}

Squamous cell carcinomas of the breast are rare. The clinical and radiological presentation is not specific. The diagnosis is histological. The treatment is based on surgery, radiotherapy and chemotherapy. The prognosis remains pejorative. Studies on larger series are necessary to codify management.

\section{Bibliography}

1. Kamra HT., et al. "Acantholytic variant of squamous cell carcinoma of breast: a rare case report". Ecancermedicalscience 5 (2011): 214.

2. Alaoui FZF., et al. "Squamous cell carcinoma of the breast: about 3 cases and review of the literature". Pan African Medical Journal 12.1 (2012).

3. Ahmed Z., et al. "Squamous cell carcinoma of the breast: about a case in Mauritania". The Pan African Medical Journal 33 (2019): 143.

4. Chahdi H and Abdellah B. "Primary epidermal carcinoma of the breast mimicking an abscess". The Pan African Medical Journal 30 (2018): 84.

5. Ziyadi M., et al. "Squamous cell carcinoma of the breast: about a case and review of the literature". The Pan African Medical Journal 24 (2016).

6. Belaabidia B., et al. "Squamous cell carcinoma of the breast review of the literature: illustrated by the report of a case". Journal de Gynécologie Obstétrique et Biologie de la Reproduction 31.1 (2002): 34-39.

7. Gauchotte G., et al. "Metaplastic carcinomas of the breast: a morphological and immunohistochemical study". Annales de Pathologie 31.1 (2011): 18-27. 
8. Mychaluk J., et al. "Primary squamous cell carcinomas of the breast: clinical study and review of the literature". Bulletin $\mathrm{du}$ Cancer 99.7-8 (2012): 771-778.

9. Mitra B., et al. "Primary squamous cell carcinoma of breast with ipsilateral axillary lymph node metastasis: An unusual case". International Journal of Surgery Case Reports 2.7 (2011): 194-197.

10. Abida A., et al. "Metaplastic breast carcinoma: About two cases". International Journal of Innovation and Applied Studies 23.3 (2018): 285-289.

\section{Assets from publication with us}

- Prompt Acknowledgement after receiving the article

- Thorough Double blinded peer review

- Rapid Publication

- Issue of Publication Certificate

- High visibility of your Published work

Website: https://www.actascientific.com/

Submit Article: https://www.actascientific.com/submission.php Email us: editor@actascientific.com

Contact us: +919182824667 